\title{
Pitfalls in Computer Statistics
}

R. R. Kinnison

March 1983

Prepared for the U.S. Department of Energy

under Contract DE-AC06-76RLO 1830

Pacific Northwest Laboratory Operated for the U.S. Department of Energy by Battelle Memorial Institute

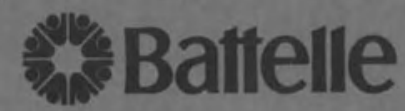

\section{$\mathrm{UC}-32$}




\title{
DISCLAIMER
}

This report was prepared as an account of work sponsored by an agency of the United States Government. Neither the United States Government nor any agency thereof, nor any of their employees, makes any warranty, express or implied, or assumes any legal liability or responsibility for the accuracy, completeness, or usefulness of any information, apparatus, product, or process disclosed, or represents that its use would not infringe privately owned rights. Reference herein to any specific commercial product, process, or service by trade name, trademark, manufacturer, or otherwise, does not necessarily constitute or imply its endorsement, recommendation, or favoring by the United States Government or any agency thereof. The views and opinions of authors expressed herein do not necessarily state or reflect those of the United States Government or any agency thereof.

\author{
PACIFIC NORTHWEST LABORATORY \\ operated by \\ BATTELLE \\ for the \\ UNITED STATES DEPARTMENT OF ENERGY \\ under Contract DE-AC06-76RLO 1830
}

\begin{tabular}{|c|c|}
\hline \multicolumn{2}{|c|}{$\begin{array}{c}\text { National Technical Information Service } \\
\text { United States Department of Commerce } \\
5285 \text { Port Royal Road } \\
\text { Springfield, Virginia } 22161\end{array}$} \\
\hline \multicolumn{2}{|c|}{$\begin{array}{l}\text { NTIS Price Codes } \\
\text { Microfiche A01 }\end{array}$} \\
\hline \multicolumn{2}{|c|}{ Printed Copy } \\
\hline Pages & $\begin{array}{l}\text { Price } \\
\text { Codes }\end{array}$ \\
\hline $001-025$ & $\mathrm{~A} 02$ \\
\hline $026-050$ & $\mathrm{~A} 03$ \\
\hline $051-075$ & $\mathrm{~A} 04$ \\
\hline $076-100$ & A05 \\
\hline $101-125$ & A06 \\
\hline $126-150$ & $A 07$ \\
\hline $151-175$ & $A 08$ \\
\hline $176-200$ & $\mathrm{~A} 09$ \\
\hline $201-225$ & A010 \\
\hline $226-250$ & $\mathrm{~A} 011$ \\
\hline $251-275$ & $\mathrm{~A} 012$ \\
\hline $276-300$ & $\mathrm{~A} 013$ \\
\hline
\end{tabular}




\section{PITFALLS IN COMPUTER STATISTICS}

R. R. Kinnison

March 1983

Prepared for

the U.S. Department of Energy

under Contract DE-AC06-76RLO 1830

Pacific Northwest Laboratory

Richland, Washington 99352 


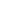




\section{CONTENTS}

1.0 INTRODUCTION . . . . . . . . . . . . . . . . . . 1

2.0 THE PROBLEM. . . . . . . . . . . . . . . . . . . . 2

3.0 TYPICAL SOLUTIONS. . . . . . . . . . . . . . . . . 3

3.1 DOUBLE PRECISION. . . . . . . . . . . . . . . . 3

3.2 THE TWO PASS METHOD .................... . 4

3.3 DATA SCALING. . . . . . . . . . . . . . . . . . 4

3.4 THE NO NAME METHOD...................... 5

4.0 EXAMPLE. .......................... . . 5

5.0 THE UPDATE ALGORITHM . . . . . . . . . . . . . . . . . . . . . . . 7

6.0 REgRESSION COMPUTATIONS. . . . . . . . . . . . . . . . 11

7.0 COMPUTERS WITH OTHER WORD SIZES. . . . . . . . . . . . 12

8.0 CONCLUSIONS. . . . . . . . . . . . . . . . . . . 13

9.0 REFERENCES ......................... 13

APPENDIX A - SUM OF SQUARES COMPUTER PROGRAM . . . . . . . . . . A-1

APPENDIX B - UPDATE COMPUTER PROGRAM ............... B- 1 


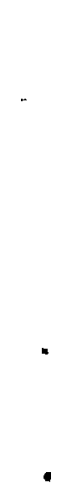




\section{PITFALLS IN COHPUTER STATISTICS}

\subsection{INTRODUCTION}

This monograph discusses the computation of sums of squares, one of the most common statistical computations, and also one of the most sensitive quantities to finite numerical representation errors. Examples show that the computational device as well as the form of the mathematical formulas are an important consideration.

Small computers are fun to use and the challenge of making a computer perform routine tasks is an avocation of scientists with access to such machines. Most scientists study statistics in order to apply this science to problems encountered in their own fields. The scientist is not concerned with the structure of statistics as an end in itself, and he is naive in numerical analysis and computer science. It is natural for him to program a computer to do a task in the same way it would be accomplished with pencil and paper. Unfortunately, it is not always accurate to program a computer in this way. Thus, those who use smali computers for scientific work often unwittingly introduce computational errors into their work.

Truncation and roundoff errors, and finite numerical representation errors in computer hardware are common phenomena. Computer scientists and numerical analysts devote time to studying the effects of such errors and to devising numerical methods to compensate for such errors. The importance of this problem can be judged by the fact that textbooks of computing algorithms designed for smal1 computers are now available, for example Nash (1979). The earliest reference to such problems is Stegun and Abramowitz (1956). Other early references are Welford (1962), an anonymous (1968) magazine article, and Forsythe (1970). None of these references deal exclusively with roundoff error in statistical computations. They are primarily concerned with errors in computing mathematical functions. 


\subsection{THE PROBLEM}

In statistics courses, one learns the following identities, used in computing the variance of a set of numbers:

$$
\begin{aligned}
& \sum_{i=1}^{n}\left(x_{i}-\bar{x}\right)^{2}= \\
& \sum_{i}^{n} x_{i}^{2}-\left(\sum_{i}^{n} x_{i}\right)^{2} / n= \\
& \sum_{i}^{n} x_{i}^{2}-n(\bar{x})^{2} .
\end{aligned}
$$

Formulas (1b) and (1c) are used with calculators which have few memory registers. Their utility stems from the fact that the data needs to be keyed into a machine only once. Each data entry is counted, and the sum of the data and the sum of the data squared are simultaneously accumulated. At the end of data entry, the quantities available are $n,\left[x^{2}\right.$, and $[x$. From these numbers, formula (1b) or (1c) can be completed. On the other hand, if formula (1a) is used, the data must be entered twice: once to compute the mean, and a second time to compute the deviations from the mean, $\left(x_{i}-\bar{x}\right)$. Then, these deviations must be squared and summed to get (1a). An estimate of the variance of $n$ data values is calculated as $1 / n-1$ times (1a), (1b) or (1c). The standard deviation is the square root of the variance.

This can be quite laborious, and anyone who has computed by (1a) on small calculators appreciates its disadvantage. It may be naively assumed that use of (1a) is discouraged due to lack of efficiency for larger computers as we 11. However, textbooks for home computer enthusiasts, such as Poole (1977, 1980), recommend the one pass method, as do some of the texts written to teach statistics to scientists, such as Davis (1973).

Computational problems occur when the sum of the numbers squared, or the squared sum of the numbers contain more significant digits than are available on the computer being used. Of course, with paper and pencil as many digits as necessary are used; this solution is not available on computers. Typically, there are no clues to the lost digits in the output because the subtraction in 
formulas (1b) or (1c) frequently gives a reasonable positive result with no warnings of such numerical errors.

Computational problems have been a concern of those who promote computer software from the beginning of scientific computers. A relatively complete review of methods for computing means and variances is given by Ling (1974). Earlier, more limited, presentations of the same material are Welford (1962), Youngs and Cramer (1971), and Spicer (1972).

\subsection{TYPICAL SOLUTIONS}

The commonily used solutions to the computational problems discussed above fall into four categories. These are the use of double precision, the two pass method, data scaling, and the no name method.

\subsection{DOUBLE PRECISION}

The most common approach is to use double precision arithmetic to accumulate sums, sums of squares, and squared sums. This is the technique used in statistical packages such SPSS, BMDP, or MINITAB. In this approach, formula (1b) or (1c) is used. Computers with 32 bit word lengths typically have the equivalent of six decimal digits in single, precision, floating point arithmetic. This is not enough for accumulating squared sums and sums of squares for problems with more than about 10 data points, where each data value has three or fewer significant digits. In double precision, these machines give the equivalent of 16 decimal digits. This has been found adequate for most data sets except very large ones with many significant digits. Scientific hand calculators use 10 or 12 digit decimal computations. This has been found to almost always be adequate for the size of data sets one would enter into such a calculator.

The most common programming language on small computers is BASIC. This language, in its usual implementation, does not allow double precision arithmetic. Small computers running BASIC yield between 6 and 10 decimal digits of accuracy, depending upon the hardware and software combination, so it is difficult to generalize about statistical computing errors on these machines. The best advice is to assume computing errors will occur, unless one of the techniques discussed below is used. 


\subsection{THE TWO PASS METHOD}

Sma11 computers now come with large memory and one or more floppy disk drives; thus, it is reasonable to use a two pass algorithm on these machines. Since formula (1a) is the definition of the sum of residuals squared, it is expected that two pass algorithms would compute statistical sums of squares exactly; this is almost true. Even two passes can fail to give the correct answer with very large data sets. However, two pass algorithms are always better numerically than one pass algorithms using double precision accuracy. The main disadvantage is that it takes time to access data files twice.

The two pass algorithms can fail for very large data sets because sums of squares and sums can lose the rightmost digits from truncation when a sma 11 number is added to a large one. Suppose a computer uses exactly six decimal digits of accuracy. The largest number that can be represented exactly in such a computer is $0.999999 \mathrm{E}+6$. If unity is added (that is $0.100000 \mathrm{E}+1$ ) to this largest number, the answer is $0.100000 E+7$. This is the correct sum. If unity is again added, on this computer, $0.100000 \mathrm{E}+7+0.100000 \mathrm{E}+1=0.100000 \mathrm{E}+7$. The unity being added falls in the seventh place of accuracy of the larger number in which only six places are available. When using a pencil and paper, the number of significant digits in such cases is increased from six to seven. This is not possible on computers, and computers usualiy don't issue warnings that truncation errors are occurring.

\subsection{DATA SCALING}

One of the earliest and simplest techniques for dealing with computational problems is to subtract a constant value from all the data. It can be shown that subtracting a constant from a data set leaves the variance of the data unchanged, and reduces the mean by the value of the constant. At the end of the computations the constant is added to the mean. For example, in the data of Table 1 (page 7), 1400 is subtracted from a 17 the data values. This suggests a simple way to test for computational roundoff error. If subtracting a constant from all data gives a different variance or standard deviation than the same program yields with the original data, then a discrete numerical representation error has occurred. 


\subsection{THE NO NAME METHOD}

A number of more elegant, and more difficult, algorithms to avoid computational errors are reviewed in detail by Ling (1974). One particular method is generally accepted as best. This method has no name. First, the data is summed and divided by the sample size to calculate the mean. For calculating the sum of squares, SS, for a sample of size $n$, the.following algorithm is used with data values $x_{i}, i=1$ to $n$ :

$$
\begin{aligned}
& \text { SS } S_{i}=S S_{i-1}+\left(i x_{i}-s_{i}\right)^{2} /(i(i-1)) \\
& \text { where } 1 \leq i \leq n \\
& s S_{n}=\text { final sum of squares } \\
& s_{0}=0, \quad s S_{0}=0 \\
& s_{i}=s_{i-1}+x_{i} .
\end{aligned}
$$

The derivation of this algorithm is given in Welford (1962). It is based upon the formulas used in mathematical statistics to correct for bias.

The corresponding algorithm for calculating sums of crossproducts, used for computing covariances and correlations, replaces in formula (2) the squared term

$$
\left(i^{*} x_{i}-s_{j}\right)^{2} \quad \text { with } \quad\left(i * x_{i}-s_{x, i}\right)\left(i * y_{i}-s_{y, j}\right) \text {. }
$$

This algorithm has been found to be as accurate as the two pass algorithm. The no name method is not widely used because it requires additional programming steps and more computer memory than use of double precision. Formula (2) is limited to adding one data value at a time. Other versions allow the simultaneous addition of groups of data values.

\section{EXAMPLE}

The data in Table 1 are from the field of nuclear material control (Jaech 1973, Table 8.7), and are shipper-receiver net weights of uranium hexafluoride cylinders, the raw material for reactor fuel. This data set consists of 10 pairs of weights. These data values contain six digits, but only the last four digits change values. 
Appendix A gives the listing of a computer program (which is almost identical to Program 3-3 in Davis (1973)) that computes the variance of the data using formula (1). This program also does some regression calculations to be discussed later. The covariance and correlations are computed in this program using equations similar to formula (1), as follows:

$$
\begin{aligned}
& \operatorname{Cov}(x, y)=[(x-\bar{x})(y-\bar{y}) /(n-1) \\
& \operatorname{Cor}(x, y)=\operatorname{Cov}(x, y) /(\operatorname{SD}(x) \star \operatorname{SD}(y))
\end{aligned}
$$

The data in Table 1 were processed on a PDP 11/70 using the program of Appendix $A$ in two ways. First, the program was used in double precision. Then, program 1 ine 0002 was deleted to give single precision computations. Table 2 summarizes the results; here, $x$ represents the shipper data and $y$ represents the receiver data. The number of digits given in Table 2 corresponds to the accuracy of the computations, 7 digits in single precision and 16 in double precision. The program in Appendix A automatically gives results to the number of digits corresponding to the precision used.

The most striking thing about this example is that the variances and covariance differ by a factor of about two between the single and double precision computations. While it is easy to conclude that single precision gives incorrect answers, it is not obvious that double precision yields the correct answers. For small data sets, such as this example, hand calculations using as many digits as are necessary can verify the correct result, the double precision calculations. Note that even though incorrect, it would be easy to accept the single precision results as reasonable.

When a one pass BASIC program is applied to this data, the inaccuracy of the method is even more evident; the variance (and thus standard deviation) of $x$ are zero, and the computation of the correlation coefficient give a division by zero error message. However, the same BASIC program will give reasonable, although inaccurate, results with other data sets. When a two pass method in single precision is applied to the data in Table 1 , the results reported in Table 2 for double precision are obtained. 
TABLE 1. Net weights of uranium

hexafluoride cylinders $(\mathrm{kg})$.

\begin{tabular}{|c|c|c|}
\hline Cylinder & Shipper Weights & Receiver Weights \\
\hline 1 & 1471.22 & 1468.12 \\
\hline 2 & 1470.98 & 1469.52 \\
\hline 3 & 1470.82 & 1469.22 \\
\hline 4 & 1470.46 & 1469.26 \\
\hline 5 & 1469.42 & 1462.96 \\
\hline 6 & 1468.98 & 1470.80 \\
\hline 7 & 1469.10 & 1467.98 \\
\hline 8 & 1470.22 & 1472.28 \\
\hline 9 & 1470.86 & 1469.02 \\
\hline 10 & 1470.38 & 1470.16 \\
\hline
\end{tabular}

TABLE 2. Comparison of single and double precision computation with uranium hexafluoride data.

\begin{tabular}{|c|c|c|}
\hline Statistic & Single Precision & Double Precision \\
\hline Mean & 1470.244 & 1470.244000000000 \\
\hline Variance $x$ & 1.111111 & 0.6507377777145141 \\
\hline Std. Dev. $x$ & 1.054093 & 0.8066831953837356 \\
\hline Mean y & 1468.923 & 1468.923000000000 \\
\hline Variance y & 5.555555 & 6.017734444441481 \\
\hline Std. Dev. y & 2.357023 & 2.453107100075633 \\
\hline $\operatorname{Cov} .(x, y)$ & 0.2222222 & 0.4188533332716260 \\
\hline $\operatorname{Cor}(x, y)$ & 0.08944273 & 0.2116617860878549 \\
\hline
\end{tabular}

\subsection{THE UPDATE ALGORITHM}

None of the algorithms discussed so far addresses the problem of adding a small quantity to a large cumulative sum, the problem described in Section 3.2. A general solution to all the computational problems presented so far was found by Chan, Golub, and LeVeque (1979). A simplified version, along with an implementation in BASIC, was recently published by Nash (1981). A FORTRAN program using this algorithm is given in Appendix $A$.

The generalized updating algorithm is based upon several algebraic identities that will not be derived here; they are tedious rather than difficult to derive. Suppose two subsets of observations on a variabie $x$, one with $m$ data elements and the other with $n$. Let $T()$ represent the totals of data index by 
the values within the parentheses, and $S()$ represent the sums of squares. Then $T(a, b)$ represents the total or sum of data values with consecutive indices from a to b. Similarly, $S(a, b)$ represents a sum of squares for those data values. If an entire data set has $m+n$ values and is divided into two subsets with $m$ and $n$ values, then the first subset can be identified by the indices $(1, m)$, and the second by $(m+1, m+n)$.

Equations are required to find the quantities $T(1, m+n)$ and $S(1, m+n)$ based on quantities $T(1, m), S(1, m), T(m+1, m+n)$, and $S(m+1, m+n)$. For totals, this is given by

$$
T(1, m+n)=T(1, m)+T(m+1, m+n) .
$$

The algebra for sums of squared deviations gives

$$
\begin{array}{r}
S(1, m+n)=S(1, m)+S(m+1, m+n)+(m /(n(m+n))) * \\
{[(n / m) \star T(1, m)-T(m+1, m+n)]^{2} .}
\end{array}
$$

As a simple check of these formulas, note that (6) is identical to (2) when $n=1, S(m+1, m+1)=0$, and $T(m+1, m+1)=x(m+1)$.

Formulas (5) and (6) can be used to update the totals and sums of squares by adding data elements one at a time; that is, by letting $n$ have the value of one. However, this, as mentioned above, can add numbers of vastly different magnitudes. Formulas (5) and (6) are generalized in the sense that there are no restrictions on the values of $m$ or $n$. Errors created from making two passes through the data or from adding numbers of vastly different magnitudes can be avoided by choosing $\mathrm{m}$ and $\mathrm{n}$ to be armost equal.

In the update algorithm this is done with the use of several "stacks" of numbers. A stack is a list of items for which all insertions and all deletions are made in such a way that the items are retrieved in the reverse order to that in which they were stored. The description of the use of stacks by the update algorithm will initially use three stacks: one to store subset sizes, one to store totals, and one to store sums of squares. Let these stacks be called $n(j), t(j)$, and $s(j)$, respectively, where the $j$ within parentheses indices the. top elements of the stacks.

To start the algorithm, the first data value, $x(1)$, is read. Unity is pushed onto the sizes stack; that is, $n(1)$ is set equal to 1 . The data value is pushed onto the totals stack, $t(1)=x(1)$; and zero is pushed onto the sums 
stack, $s(1)=0$. The next data value, $x(2)$, is read into the program and the index $j$ is incremented; that is, $j=2$. Unity is again pushed onto the sizes stack, $n(2)=1$; the data value is pushed onto the totals stack, $t(2)=x(2)$; and zero is pushed onto the sums stack, $s(2)=0$. There are now two equal sized subgroups of the data stored in the stacks, using the terminology of formula (5), $t(1)=T(1,1)=x(1)$ and $t(2)=T(2,2)=x(2)$. At this point formulas (5) and (6) can be used to combine the two subgroups into a single subgroup of size 2 .

The algorithm compares the two topmost numbers in the sizes stack, $n(j-1)$ and $n(j)$. If they are equal, the stacks are collapsed using formulas (5) and (6). In our example, $n(1)=n(2)=1$, so the stacks are collapsed. Formula (5) is used to collapse the totals stack giving $t(1)=T(1,2)$; likewise from formula $(6), s(1)=s(1,2)$. Subsample sizes are combined using $n(j-1)=n(j-1)+n(j)$, and it follows that $n(1)=2$. Finally, the stack counter is decremented, $j=j-1$, giving $j=1$.

The next data value, $x(3)$, is read and the process is repeated: $j=j+1=2, n(j)=1, t(j)=x(3)$, and $s(j)=0$. The sizes stack is checked for equality of the top two elements, $n(j-1)$ and $n(j)$. At this point $j=2$, $n(1)=2$, and $n(2)=1$, so the sizes are unequal and the stacks are not collapsed. The fourth data point is read in, and pushed on to the stacks just like the third data value was. Now $n(2)=n(3)=1$ so the stacks are collapsed, giving $n(2)=2, t(2)=x(3)+x(4)=T(3,4)$, and $s(2)=s(3,4)$, and $j=2$. The top two entries of the sizes stack are again compared, and since $n(1)=n(2)=2$, the collapsing is again performed. After this step $j=1$, $t(j)=T(1,4), s(j)=s(1,4)$, and $n(j)=4$. Whenever $j=1$, the stack collapsing is terminated. Figure 1 is a schematic of this process for the totals stack.

In Figure 1 a pattern is seen that determines the stack size required for any given data set. The maximum number of data values that can be accommodated in a stack of size $j$ is 2 to the $j$ th power minus 1 . If $j=10$, then 1023 data values can be read in before stack overflow occurs, if $j=12$, the number is 4095, and if the stacks are 20 elements long, over a miliion data values can be handled. The pattern of using stacks, as so far presented, will yield $T(1, m+n)$ only if $m+n$ is a power of 2. For any other total sample size, formulas (5) 


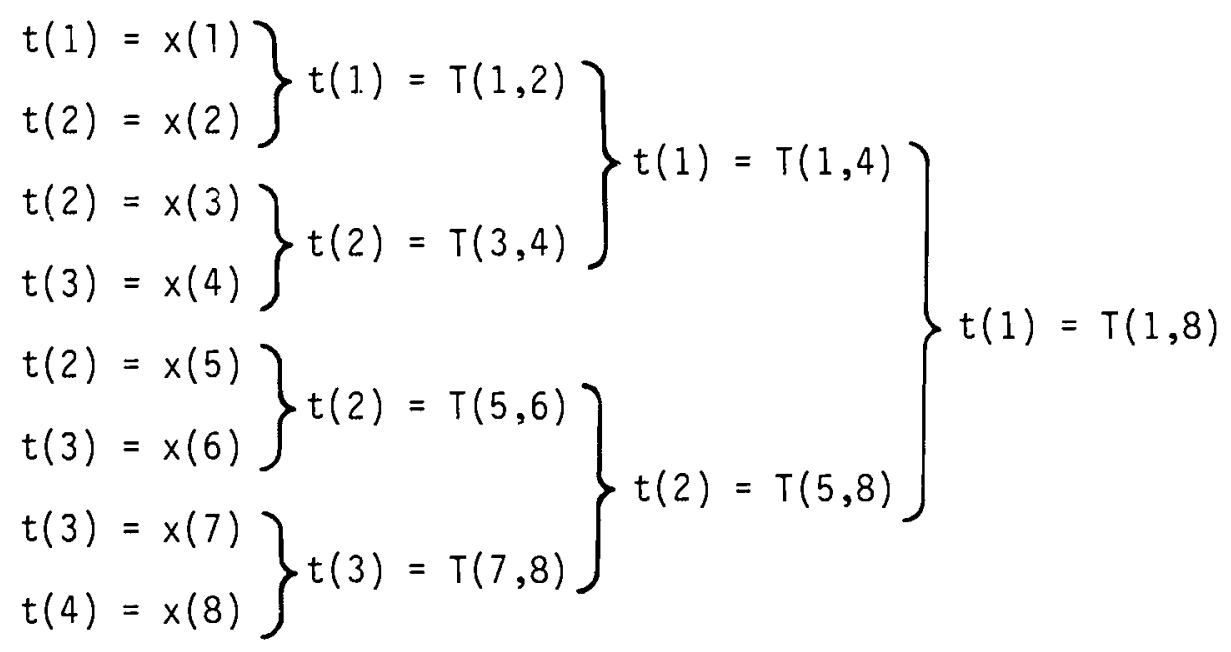

FIGURE 1. Contents of totals stack for 8 data values.

and (6) are used at the end of data entry to collapse the stacks completely using unequal subset sizes. Here is the only weakness in the update algorithm. The problem of adding small numbers to large numbers, discussed above, occurs whenever these final subsets sizes are vastly different. The worst case condition occurs when the sample size is 1 plus a power of 2 . For example, if there are 4097 data values, then at the end of data entry $n(1)=4096$ and $n(2)=1$. When a pattern such as $n(1)=32, n(2)=16, n(3)=8, n(4)=4$, $n(5)=2$, and $n(6)=1$ exists, that is the total sample size is 1 less than a power of 2 , the maximum differences in subset sizes is 1 during the final collapsing of the stack structure. Real data sets will be between these extremes. Even with this flaw, the update algorithm is better than any other algorithm since the addition of small and large numbers occurs only once rather than repeatedly. Chan, Golub and LeVeque (1979) claim the update algorithm is even better than the two pass algorithm.

The FORTRAN computer program presented in Appendix $B$ for the update algorithm is a slight extension of the algorithm as so far discussed. Two variables are entered at a time, that is a data value consists of the paired values $(x(i), y(i))$. Additional stacks are used for the $y^{\prime}$ s and another stack is used for the $x, y$ crossproduct, so that the covariance and correlation of $x$ and $y$ can be computed. The crossproduct computation is an extension of formula (6) in which the squared term of $(6)$ is replaced by two terms multiplied. One of these two is derived from the $x^{\prime} s$ and the other from the $y^{\prime} s$. Additional notation is 
needed to keep straight which sums and totals are associated with each variable. Let $T(x: 1, m)$ denote the total for a subset of $x^{\prime} s$ of size $m$, and let $T(y: 1, m)$ be the corresponding total for the $y^{\prime} s$. The sums of squares can likewise be denoted as $s(x: 1, m)$ and $s(y: 1, m)$. Let $c(1, m)$ denote the crossproduct

$$
c(1, m)=\sum_{i=1}^{m}\left(x_{i}-\bar{x}\right)\left(y_{i}-\bar{y}\right) \text {. }
$$

The covariance of $x$ and $y$ is $c(1, m) /(m-1)$, and the correlation is the covariance divided by the product of the standard deviations of $x$ and of $y, c(1, m+n)$ may be computed in a manner analogous to Formula (6).

$$
\begin{aligned}
& c(1, m+n)=c(1, m)+c(m+1, m+n)+m /(n(m+n)) * \\
&\left(n / m^{\star} T(x: 1, m)-T(x: m+1, m+n)\right) * \\
&\left(n / m^{\star} T(y: 1, m)-T(y: m+1, m+n)\right) .
\end{aligned}
$$

The update algorithm of Appendix $B$ was executed on the data of Table 1 on a PDP $11 / 70$ in single precision. Table 3 presents the results along with the double precision results (from Table 2) rounded to seven significant digits. Table 3 shows good agreement between the results of the update algorithm and

\begin{tabular}{|c|c|c|}
\hline Statistic & Update Algorithm & Double Precision \\
\hline $\begin{array}{l}\text { Mean } x \\
\text { Variance } x \\
\text { Std. Dev. } x \\
\text { Mean y } \\
\text { Variance y } \\
\text { Std. Dev. y } \\
\text { Cov }(x, y) \\
\text { Cor }(x, y)\end{array}$ & $\begin{array}{l}1470.244 \\
0.6506880 \\
0.8066523 \\
1468.923 \\
6.017866 \\
2.453134 \\
0.4188027 \\
0.2116420\end{array}$ & $\begin{array}{l}1470.244 \\
0.6507378 \\
0.8066832 \\
1468.923 \\
6.017734 \\
2.453107 \\
0.4188533 \\
0.2116618\end{array}$ \\
\hline
\end{tabular}
double precision computations.

TABLE 3. Comparison of update algorithm and double precision computations using uranium hexafluoride data.

\subsection{REGRESSION COMPUTATIONS}

Means, variances, and correlations are only a part of statistical computations. Most statistical problems are multivariate in that many dependent and independent variables are recorded for analysis. It is obvious that formula (7) 
can be applied to each pair of multiple variables to form a dispersion or crossproducts matrix for multiple correlation or multiple regression analysis. Roundoff error in multivariate computations has been an area of concern in statistical computing for many years, and some attempts at computational efficiency have come close to the update algorithm. These lacked only the use of stacks to keep subgroups of equal size. Clarke (1971), Hawkins (1974), and Herraman (1968) give algorithms that are primarily intended for adding one data point, or a small set of points, to a large crossproducts matrix. Their algorithms can be extended to include the stack concept of the update algorithm.

The update version of formulas for several common bivariate statistics can be found within the program listed in Appendix B the corresponding "classic" formulas are in Appendix A.

\subsection{COMPUTERS WITH OTHER WORD SIZES}

The results discussed above are typical of 32 bit word computers in common usage today. A 16 bit word computer that uses two words for single precision floating point arithmetic is equivalent to a 32 bit word length computer that uses one word. A11 32 bit computers are not exactly the same, however, because a different modulus and base of the floating point representation is used. Even different software systems on a given computer can handle mathematical operations differently. These differences are minor compared to the gross truncation errors illustrated above.

After 32 bit words, the most common computer word sized are 60 and 64 bit words used in Control Data Corporation hardware. With these machines, single precision is equivalent to double precision on a 32 bit word computer. A few computer manufacturers use 24,36 and 48 bit words. Most microcomputers and home computers use the equivalent of 32 bit words by using four 8 bit words to store a single number. The BASIC interpreters on home computers introduce added complications; some use decimal arithmetic and others use binary arithmetic, and there is no commonly used number of significant digits.

The choice between accumulating a few sums in double precision or using the update algorithm depends upon the size of the problem at hand. Double precision is adequate for small to moderate sized data sets. Of course, the best way 
to cover all possibilities is to implement the update algorithm using double precision stacks.

\subsection{CONCLUSIONS}

Statistical computations such as sums of squares are easy (but tedious) to perform accurately with paper and pencil. However, the difficulty in accurately calculating these results on computers is demonstrated in Section 4 . The problem is especially acute on microcomputers, where the user does not have access to double precision variables. Calculation of sums of squares in the single precision, one pass algorithm, can give highly inaccurate results. If double precision is not available (such as in BASIC), the update algorithms presented in Section 5 should be used.

\subsection{REFERENCES}

Anonymous. 1968. Small differences can lead to big errors. Electronic Design News, Nov. 25, 1968, pp. 14-17.

Chan, T. F., G. H. Golub, and R. J. LeVeque. 1979. Updating Formulae and a Pairwise Algorithm for Computing Sample Variances. Report No. STAN-CS-79-773, Department of Computer Sciences, Stanford University, Stanford, Ca.

Clarke, M.R.B. 1971. Algorithm AS41, Updating the sample mean and dispersion matrix. Applied Statistics 20:206-209.

Davis, S. C. 1973. Statistics and Data Analysis in Geology. John Wiley and Sons, New York, NY.

Forsythe, G. E. 1970. Pitfalls in computation, or why a math book isn't enough. Amer. Math. Monthly 77(9):931-956.

Hawkins, D. M. 1974. Algorithm AS72, Computing mean vectors and dispersion matrices in multivariate analysis of variance. Applied Statistics $23(2): 234-238$.

Herraman, C. 1968. Algorithm AS-12, Sums of squares and products matrix. Applied Statistics 17(3):289-292.

Jaech, J. L. 1973. Statistical Methods in Nuclear Material Control. TID-26298, National Technical Information Service, Springfield, VA.

Ling, R. F. 1974. Comparison of several algorithms for computing sample means and variances. J.Amer. Stat. Assoc. 69(348):859-866. 
Nash, J. C. 1979. Compact Numerical Methods for Computers. Halstead Press (John Wiley and Sons), New York, NY.

Nash. J. C. 1981. The micro mathematician. Interface Age 6(9):40-42.

Poole, L. and M. Borchers. 1977. Some Common BASIC Programs. Adam Osborne and Associates, Inc., Berkeley, CA.

Poole, L. 1980. Practical BASIC Programs. Osborne/McGraw-Hill, Berkeley, CA.

Spicer, C. C. 1972. Algorithm AS-52, Calculation of power sums of deviations about the mean. Applied Statistics 21(2):226-227.

Stegun, I. A. and M. Abramowitz. 1956. Pitfalls in computation. J. Soc. Appl. Math. 4(4)207-219.

Welford, B. P. 1961. Note on a method for calculating corrected sums of squares and products. Technometrics 4(3):419-420.

Youngs, E. A. and E. M. Cramer. 1971. Some results relevant to choice of sum and sum-of-product algorithms. Technometrics 13(3):657-665. 
APPENDIX A

SUM OF SQUARES PROGRAM 
APPENDIX A

SUM OF SQUARES RRQGRAM

0001

0002

0003

0004

0005

0006

0007

0008

0009

0010

0011

0012

0013

0014

0015

0016

0017

C

C

C

C

C

1

$\mathrm{C}$
$\mathrm{C}$
$\mathrm{C}$
$\mathrm{C}$
$\mathrm{C}$

0018

0019

0020

0021

0022

0023

0024

0025

0026

0027

0028

0029

$c$

$\mathrm{C}$

C

2

PROGRAM SUMS

IMPLICIT DOUBLE PRECISION $(A-H, O-Z)$

PROGRAM TO PERFORM MEANS, VARI AMCES, CORRELATIONS, AND LINEAR REGRESSION USING 'MACHIME FORMULAS', THAT IS THE SUMS OF SQUARES MINUM SQUARE OF SLMS TYPE CALCULATIONS.

SUMX $=0$.

SUMY $=0$.

SUMX2 $=0$.

SUMY $2=0$.

SUMXY $=0$.

$\mathrm{N}=0$

OPEN(UNI T $=1$, NAME $=$ 'AVE. DA'T', TYPE = 'OLD' , READONLY)

$\operatorname{READ}(1, *, E N D=2) X, Y$

$\mathrm{N}=\mathrm{N}+1$

SUMX $=S U M X+X$

$S U M Y=S U M Y+Y$

SUMX2 $2=$ SUMX $2+X * X$

SUMY $2=S U M Y 2+Y * Y$

SUMXY $=S U M X Y+X * Y$

GO TO 1

END OF DATA INPUT

$* * * * * * * * * * * * * * * * * * * * * * * * * * * * * * * * * * * * 10$

OUTPUT FOR CORRELATION AND DESCRIPTION OF $X$ AND $Y$

$X N=F L O A T(N)$

TYPE *, 'NUMBER OF DATA VALUES $=1, N$

$X M E A N=S U M X / X N$

TYPE *, 'MEAN $X=1$, XMEAN

YMEAN $=$ SUMY $/ X N$

TYPE *, 'MEAN $Y=1, Y M E A N$

DENOM $=$ SUMX2-SUMX*SUMX/XN

$X V A R=D E N O M /(X N-1$.

TYPE *, 'VAR $(X)=1, X V A R$

$X S D=S Q R T(X V A R)$

TYPE *, 'S.D. $X=1, X S D$

YVAR $=(S U M Y 2-S U M Y * S U M Y / X N) /(X N-1$. 
0030

0031

0032

0033

0034

0035

0036

0037

0038

0039

0040

0041

0042

0043

0044

0045

0046

0047

0048

0049

0050

0051

0052

0053

0054

0055

0056

0057

0058

0059

0060

0061

0062

0063

0064
TYPE *, ' $V A R(Y)=1, Y V A R$

$Y S D=S Q R T(Y V A R)$

TYPE *, 'S.D. $Y=1, Y S D$

COV $=(S U M X Y-S U M X * S U M Y / X N) /(X N-1$.

TYPE *, 'COVARIANCE $(X, Y)=1, \mathrm{COV}$

$\mathrm{COR}=\mathrm{COV} /(\mathrm{XSD} * Y S D)$

TYPE *, $\operatorname{CORR}(X, Y)=1, C O R$

TYPE *, 'SUM OF $X$ VALUES $=1$, SUMX

TYPE *, 'SUM OF Y VALUES $=1$, SUMY

TYPE *, ' SUM $X$-SQUARED $=$ ', SUMX2

TYPE *, 'SUM $Y$-SQUARED $=1$, SUMY2

TYPE *, 'SUM $X * Y=1$, SUMXY

END DESCRIPTION OF VARIABLES

$* * * * * * * * * * * * * * * * * * * * * * * * * * * * * * * * *$

OUTPUT FOR LINEAR REGRESSION

$B=(S U M X Y-S U M X * S U M Y / X N) / D E N O M$

$A=Y M E A N-B * X M E A N$

TYPE *, 'REGRESSION LINE: $Y=1, A, 1+1, B, 1 * X$ '

ANALYSIS OF VARIANCE FOR REGRESSION

$S S R E G=A * S U M Y+B * S U M X Y-X N * Y M E A N * Y M E A N$

SSRES $=$ SUMY $2-(A *$ SUMY+B* SUMXY $)$

REGMSE $=S S R E G$

RESMSE $=S S R E S /(X N-2$.

$F=R E G M S E / R E S M S E$

TYPE *, 1 '

TYPE *, 'SOURCE SUM-SQUARES D.F. MSE F-VALUE'

TYPE *, 'REGRESSION ', SSREG,' 1 ', REGMSE, $F$

TYPE *, 'RESIDUAL ', SSRES, $N-2$, RESMSE

TYPE *, ' '

END OF ANOV

$S D=S Q R T(R E S M S E)$

TYPE *, 'RESIDUAL STANDARD DEV IATION= ', SD

SDSLP $=$ SQRT (RESMSE/DENOM)

TYPE *, 'STANDARD ERROR OF SLOPE $=$ ', SDSLP

SDINT $=$ SQRT (RESMSE* SUMX 2/ (XN*EENOM))

TYPE *, 'STANDARD ERROR OF INTERCEPT= ', SDINT

COVSI $=-$ RESMSE *XMEAN/DENOM

TYPE *, 'COVARI AMCE (SLOPE, INTERCEPT) =1, COVSI

R2=SSREG/ ( SSREG+SSRES)

TYPE *, 'COEFFICIENT OF DETEPMINATION $\left(R^{* *} 2\right)=1, R 2$

C

C PREDICTION AND PREDICTION ERROR 


\begin{tabular}{|c|c|c|}
\hline $\begin{array}{l}0065 \\
0066 \\
0067 \\
0068 \\
0069 \\
0070 \\
0071 \\
0072 \\
0073\end{array}$ & 20 & $\begin{array}{l}\text { TYPE *, 'PRED I CTED Y AT } X=1 \\
\text { ACCEPT *, } X \\
Y=A+B^{*} X \\
\text { DEV }=X-X M E A N \\
S=1 .+1 . / X N+D E V * D E V / D E N O M \\
S=S Q R T(S) * S D \\
\text { TYPE *, 'PRED ICTED Y AT } X=1, X, ' I S ', Y, ' W I T H \quad S D=1, S \\
\text { GO TO } 20 \\
\text { END }\end{array}$ \\
\hline
\end{tabular}



APPENDIX B

UPDATE COMPUTER PROGRAM 
APPENDIX B

UPDAIE COMPUTER PROGRAM

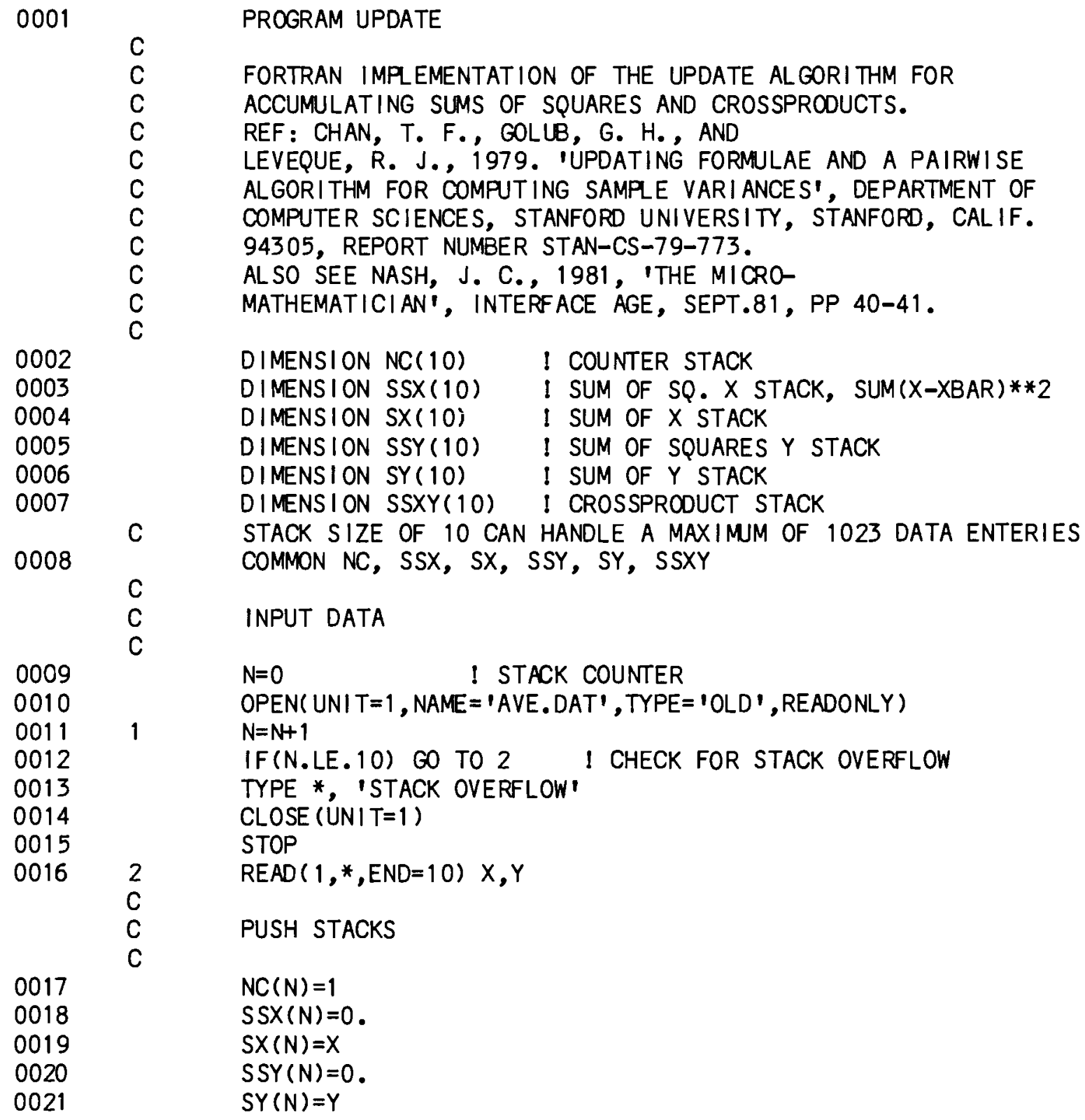

0021

PROGRAM UPDATE

FORTRAN IMPLEMENTATION OF THE UPDATE ALGORITHM FOR ACCUMULATING SUMS OF SQUARES AND CROSSPRODUCTS.

REF : CHAN, T. F., GOLLB, G. H., AND LEVEQUE, R. J., 1979. 'UPDATING FORMULAE AND A PAIRWISE ALGORITHM FOR COMPUTING SAMRLE VARIANCES', DEPARTMENT OF COMPUTER SCIENCES, STANFORD UNIVERSITY, STANFORD, CALIF. 94305, REPORT NUMBER STAN-CS-79-773.

ALSO SEE NASH, J. C., 1981, 'THE MICRO-

MATHEMATICIAN', INTERFACE AGE, SEPT.81, PP 40-41.

C 
$\operatorname{SSXY}(N)=0$.

STACK COLLAPSING

0024

0025

0026

0027

0028

0029

0030

0031

0032

0033

0034

0035

0036

0037

0038

0039

0040

0041

0042

0043

0044

0045

0046

0047

0048

0049

0050

0051

C

C

C

C

C

10

IF (N.EQ.1) GO TO 1

! CAN'T COLLAPSE A SIZE 1 STACK

IF STACK IS NOT READY TO COLLAPSE, GO FOR MORE DATA

IF $(N C(N)$. NE. NC(N-1)) GO TO 1

CALL COLLAP(N)

GO TO 3

END OF INPUT ROUTINE

$* * * * * * * * * * * * * * * * * * * * * * * * * * * * * * * * * * * * * * * * * * * * * * * * * * * * * * * * *$

OUTPUT ROUTINE

$\mathrm{N}=\mathrm{N}-1$

CLOSE (UNIT=1)

IF(N.GT.1.OR.NC(1).GT.1) GO TO 11

TYPE *, 'NOT ENOUGH DATA'

STOP

11

CALL COLLAP(N)

C

IF(N.GT.1) GO TO 11 ! LOOP TO TERMINATE STACKS

$N=N C(1)$

$A N=F L O A T(N-1)$

TYPE *, 'NUMBER OF DATA PAIRS $=1, N$

$X M E A N=S X(1) / F L O A T(N)$

TYPE *, 'SUM OF X''S=1,SX(1),' MEAN $X=1, X M E A N$

$X V A R=S S X(1) / A N$

$S D X=S Q R T(X V A R)$

TYPE *, ISUM OF SQUARES OF $X=1, S S X(1)$

TYPE *, 'VARIANCE OF $X=1, X V A R, 1$ STD DEV. OF $X=1$, SDX

YMEAN $=S Y(1) / F L O A T(N)$

TYPE *, 'SUM OF Y''S=1,SY(1),' MEAN $Y=1, Y M E A N$

YVAR $=S S Y(1) / A N$

SDY=SQRT (YVAR)

TYPE *, ' SUM OF SQUARES OF $Y=1, S S Y(1)$

TYPE *, 'VARIANCE OF $Y=1$, YVAR,' STD DEV. OF $Y=1$, SDY

COV $=S S X Y(1) / A N$

$\mathrm{COR}=\mathrm{COV} /(\mathrm{SDX} * \mathrm{SDY})$

TYPE *, 'COVARIANCE $(X, Y)=1$, COV,' CORRELATION $(X, Y)=1$, COR

$\mathrm{C}$

C

C

C

C

0052

0053

0054

END OF CORRELATIONS AND SINGLE VARIABLE OUTPUT

BEGIN REGRESSION PART OF PROGRAM

COMPUTE SLOPE AND INTERCEPT

$B=\infty R * S D Y / S D X$

$A=Y M E A N-B * X M E A N$

TYPE *, 'REGRESSION LINE: $Y=1, A, 1+1, B, 1 * X '$ 


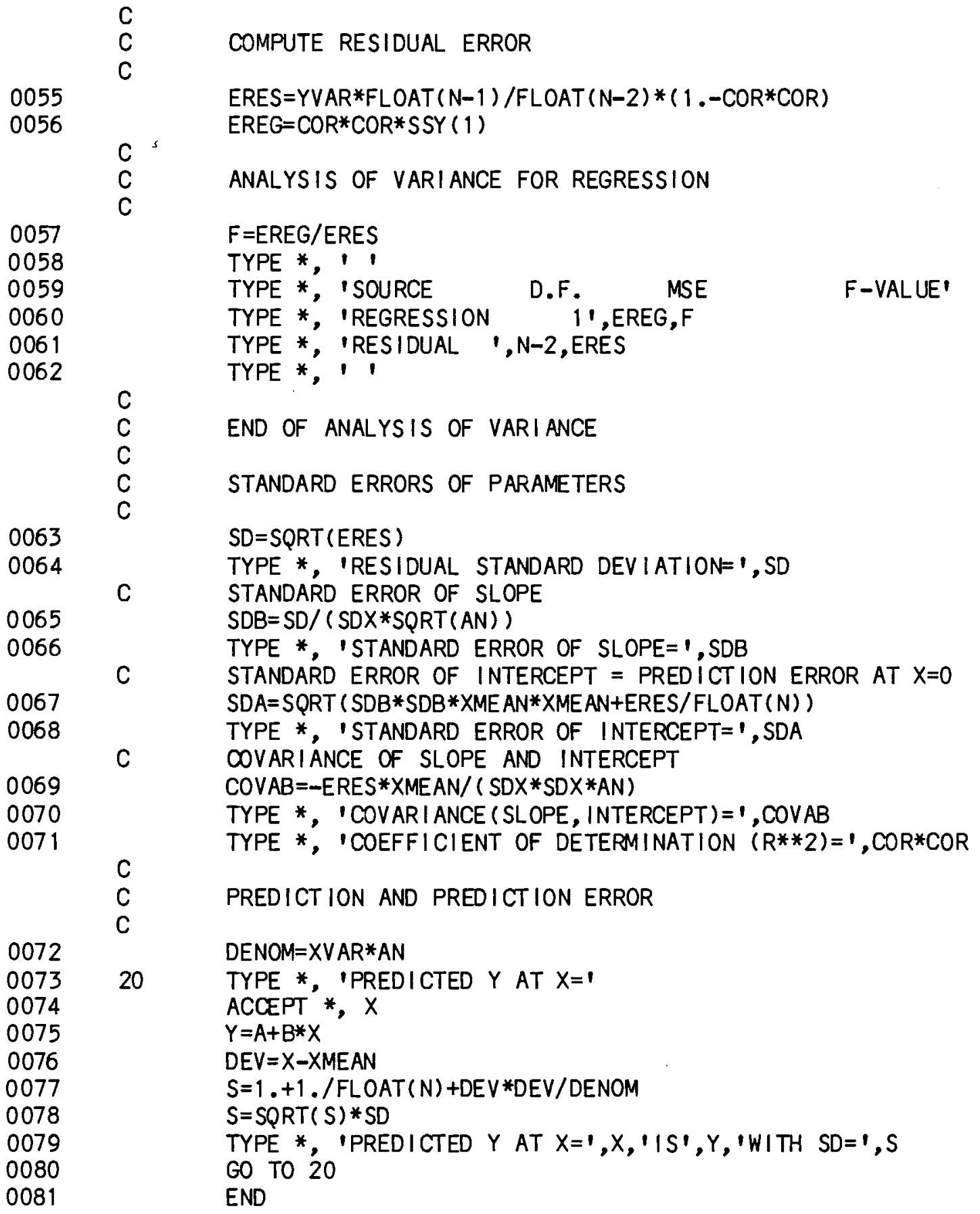


0001

0002

0003

0004

0005

0001

C

C

0002

0003

0004

0005

0006

0007

0008

0009

0010

0011

0012

0013

0014

0015

0016

C
SUBROUTINE STACK $(N, A, B)$

DIMENSION $A(1)$

$A(N-1)=A(N-1)+A(N)+B$

RETURN

END

SUBROUT INE COLLAP(N)

SUBROUTINE TO COLLAPES STACKS FOR UPDATE ALGORITHM

COMMON NC(10), SSX(10), SX(10), SSY(10), SY(10), SSXY(10)

$E=N C(N)$

$\mathrm{F}=\mathrm{NC}(\mathrm{N}-1)$

$H=F /\left(E^{*}(E+F)\right)$

COUNTER STACK IS AN INTEGER ARRAY AND THUS

CANNOT BE COLLAPSED WITH SUBROUTINE STACK.

$N C(N-1)=N C(N-1)+N C(N) \quad$ ! COLLAPSE COUNTER STACK

$C=E * S X(N-1) / F-S X(N)$

CALL STACK $(N, S S X, H * C * C)$ ! COLLAPSE SUM SQUARES $X$ STACK

CALL $\operatorname{STACK}(N, S X, 0$.

$G=E * S Y(N-1) / F-S Y(N)$

CALL STACK $\left(N, S S Y, H^{*} G^{*} G\right)$ ! COLLAPSE SUM SQUARES Y STACK

CALL STACK $(N, S Y, 0$.$) I COLLAPSE SUM Y'S STACK$

CALL STACK $(N, S S X Y, H * C * G)$ ! COLLAPSE CROSSPRODUCT STACK

$\mathrm{N}=\mathrm{N}-1$

RETURN

END 
DISTRIBUTION

No. of

Copies

OFFSITE

Dr. Robert L. Watters

Office of Health and

Environmental Research

Washington, DC 20545

27 DOE Technical Information Center

Dr. Forest L. Miller

Desert Research Institute

Las Vegas, NV 89109

\section{ONSITE}

DOE Richland Operations Office

H. E. Ransom

26 Pacific Northwest Laboratory

R. 0. Gilbert

R. R. Kinnison (15)

C. A. Oster

B. E. Vaughan

C. R. Wats on

Publishing Coordination (2)

Technical Information (5) 


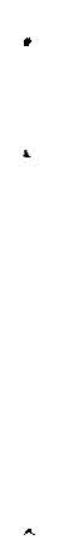

